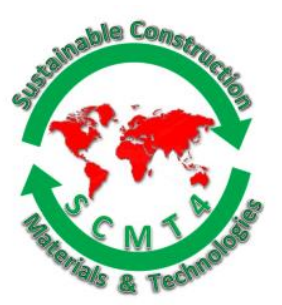

\title{
Autogenous Shrinkage of Low Water-Binder Ratio Cement Pastes with Supplementary Cementitious Materials
}

\author{
Y. Lv ${ }^{* 1 a}$, H. Huang ${ }^{2 a}$, G. Ye ${ }^{1 b, 2 b}$ and G. De Schutter ${ }^{1 c, 2 c}$ \\ ${ }^{I}$ Magnel Laboratory for Concrete Research, Department of Structural Engineering, Ghent University, \\ Technologiepark-Zwijnaarde 904, 9052 Gent, Belgium \\ ${ }^{2}$ Microlab, Faculty of Civil Engineering and Geosciences, Delft University of Technology, P.O. Box \\ 5048, 2600 GA Delft, The Netherlands. ${ }^{* 1 a}$ Email: <yang.lv@ugent.be>, ${ }^{2 a}$ Email: <h.huang- \\ 1@tudelft.nl>, 1,2bEmail:<G.Ye@tudelft.nl>,,2cEmail: <Geert.DeSchutter@ugent.be>
}

\begin{abstract}
High-performance cementitious materials are sensitive to early age cracking, mainly due to the large magnitude of autogenous shrinkage, which is closely related to the internal relative humidity (RH) decrease and capillary pressure induced by self-desiccation in the cement matrix. However, there is debate about the determination of time-zero, the time at which autogenous shrinkage begins to develop, which causes great difficulty in comparing the results provided in the exiting researches.

This study presents an accurate determination of time-zero based on the relationship between the internal RH and autogenous shrinkage of cementitious materials. According to the time-zero, the effect of replacements of cement by supplementary cementitious materials on the autogenous shrinkage was investigated for the early age cement pastes with low water/binder ratio.

The autogenous shrinkage was conducted according to the standard method ASTM C1698. Internal $\mathrm{RH}$ was performed on the sealed cement pastes at very early age by conventional method of hygrometer. Setting time was determined by the Vicat needle apparatus according to the standard method ASTM C191. The results could potentially explain the mechanism of autogenous shrinkage at early age in mixtures with supplementary cementitious materials.
\end{abstract}

\section{INTRODUCTION}

Autogenous shrinkage is of increasing concern, as it can be responsible for cracking especially in early age high performance concrete, which is characterized by low water/binder (w/b) ratio, high cement content and the incorporation of mineral admixture additions and superplasticizer. When the concrete behaves like a fluid, i.e., during the very early age, its volumetric changes are usually not of a great concern in terms of stress generation because the concrete deforms plastically without generating stresses. However, once it has transformed to a visco-elastic solid, the stress is generated [Bentur 2001]. This transition is very important with respect to the initiation of autogenous shrinkage strain and induced 
stress. Due to the complex fluid-solid transition process, it is difficult to determine the initiation point of autogenous shrinkage. According to [Tazawa et al. 1991; Justnes et al. 1994], the driving force of autogenous shrinkage comes from the capillary tension caused by self-desiccation in the pore structure of concrete as the moisture is consumed during the hydration process. It supplies a potential way to determine the initiation point of autogenous shrinkage by detecting the occurrence of self-desiccation, which is linked to the internal relative humidity $(\mathrm{RH})$ development of cement paste system.

It is known that supplementary cementitious materials (SCMs) can modify the mechanical characteristics of concrete, durability, and non-autogenous phenomena [Malhotra and Mehta 1996]. The improvements produced by the SCMs can also modify the autogenous phenomena in concrete. Blast furnace slag and fly ash have played an important part in the production of HPC [Swamy 1997; Krishnamoorthy et al. 2002]. Few studies investigated the influence of zeolite on the autogenous shrinkage of concrete, but no common conclusion was obtained [Bílek et al. 2002; Ghourchian et al. 2013]. This study attempts to study the correlation between autogenous shrinkage and the self-desiccation of cement paste, aiming to present an accurate determination of time-zero based on the relationship between the internal $\mathrm{RH}$ and autogenous shrinkage of cementitious materials. According to the time-zero, the effect of replacements of cement by three supplementary cementitious materials, blast-furnace slag, fly ash and zeolite, on the selfdesiccation and autogenous shrinkage was investigated for the early age cement pastes with low water/binder ratio.

\section{EXPERIMENTAL INVESTIGATION}

\section{Materials}

Ordinary Portland Cement (OPC) CEM I 52.5.N was used in this study. The blast-furnace slag (BFS), fly ash (FA) and zeolite was used as supplementary cementitious materials (SCMs). The chemical composition of each material was analyzed by means of X-ray fluorescence (XRF) technique, and the results are shown in table 1. Figure 1 provides the particle size distribution of the cement and SCMs used in this study. The zeolite shows a finer particle size than the cement. FA shows a coarser particle size than the cement.

Cement pastes blended with or without $20 \%$ SCMs by weight with a low water to binder $(\mathrm{w} / \mathrm{b})$ ratio of 0.25 were prepared. The mixture design is shown in Table 2 . A polycarboxylate-based superplasticizer (Glenium 51, Conc. 35\% BASF) was used to modify the fluidity of cement pastes.

Table 1. Chemical and Bogue composition of cement and SCMs (- not available or not applicable)

\begin{tabular}{|c|c|c|c|c|c|c|c|c|c|c|c|c|}
\hline Material & \multicolumn{6}{|c|}{ Chemical composition/ \% by weight } & \multicolumn{3}{c|}{ Bogue composition } \\
\cline { 2 - 14 } & $\mathrm{CaO}$ & $\mathrm{SiO}_{2}$ & $\mathrm{Al}_{2} \mathrm{O}_{3}$ & $\mathrm{Fe}_{2} \mathrm{O}_{3}$ & $\mathrm{SO}_{3}$ & $\mathrm{Na}_{2} \mathrm{O}$ & $\mathrm{K}_{2} \mathrm{O}$ & $\mathrm{MgO}$ & $\mathrm{C}_{3} \mathrm{~S}$ & $\mathrm{C}_{2} \mathrm{~S}$ & $\mathrm{C}_{3} \mathrm{~A}$ & $\mathrm{C}_{4} \mathrm{AF}$ \\
\hline Cement & 63.12 & 18.73 & 4.94 & 3.99 & 3.07 & 0.41 & 0.77 & 1.02 & 66.92 & 3.22 & 6.34 & 12.14 \\
\hline BFS & 40.01 & 35.75 & 10.70 & 0.28 & 1.39 & 0.23 & 0.36 & 9.99 & - & - & - & - \\
\hline FA & 3.02 & 54.19 & 23.50 & 7.92 & 0.94 & 1.08 & 3.38 & 1.92 & - & - & - & - \\
\hline Zeolite & 10.01 & 55.00 & 15.94 & 6.95 & 0.19 & - & 9.26 & - & - & - & - & - \\
\hline
\end{tabular}




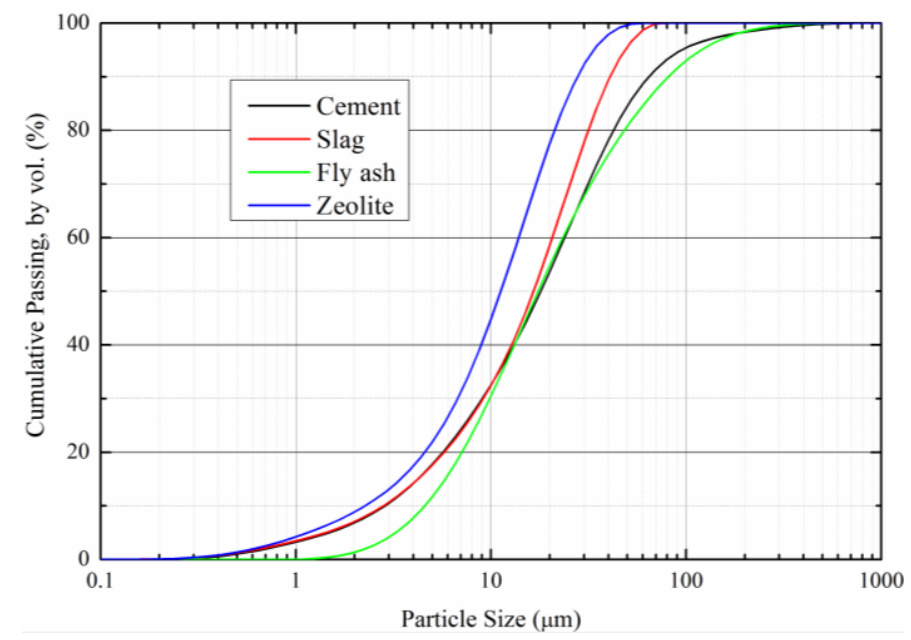

Figure 1. Particle size distribution of cement and SCMs

Table 2. Mixtures design

\begin{tabular}{|c|c|c|c|}
\hline Sample & $\begin{array}{c}\text { SCM Replacement } \\
\text { (wt.\% of binder) }\end{array}$ & Water/binder & $\begin{array}{c}\text { Superplasticizer } \\
\text { (wt.\% of binder) }\end{array}$ \\
\hline Control & 0 & \multirow{2}{*}{0.25} & 1.0 \\
\hline FA-20 & 20 & & 1.0 \\
\hline Slag-20 & 20 & & 1.0 \\
\hline Zeolite-20 & 20 & & 1.4 \\
\end{tabular}

\section{TESTING PROGRAMS}

\section{Hydration heat}

The hydration heat flow of cement pastes blended with and without SCMs was measured by an isothermal calorimeter at $20{ }^{\circ} \mathrm{C}$ (Thermometric). About $10 \mathrm{~g}$ of freshly mixed pastes were poured into glass vials immediately after the mixing. The calorimetry results are normalized by gram of binder in the mixture.

\section{Final Setting}

Final setting of cement paste was determined using the Vicat needle test according to ASTM C 191 [2013].

\section{Internal Relative Humidity}

The internal equilibrium relative humidity $(\mathrm{RH})$ of hydrating cement paste was measured on two independent sealed paste specimens by the Rotronic hygroscope station, which is equipped with a Pt-100 temperature sensor and a DMS-100 H relative humidity sensor. During the measurement, the stations were immersed in water bath to maintain the temperature of the sample and the sensor at $20 \pm 0.1{ }^{\circ} \mathrm{C}$. The sensors were calibrated before measurement with standard salt solutions with known RH in the range 65$95 \%$ at $20{ }^{\circ} \mathrm{C}$. This gives a measurement accuracy of $\pm 0.5 \%$ in the absolute RH. More detailed information about the test procedure of the internal RH measurement can be found in the study of Huang and Ye [2014]. The data were logged every $3 \mathrm{~min}$ automatically, and the measurement was continued until the age of 4 to 6 days. 


\section{Autogenous Shrinkage}

Autogenous shrinkage of cement paste was measured by the corrugated tube method, which was introduced by Jensen and Hansen [1995] and standardized as ASTM C1698 [2009]. The fresh mixed cement paste was casted into the corrugated tubes of $420 \mathrm{~mm} \varphi 29 \mathrm{~mm}$ and vibrated. For each mixture, three specimens were prepared and placed in a dilatometer rig (immersed in a temperature-controlled glycol bath), which was equipped with linear variable differential transformer (LVDT) with a measuring accuracy of $2.5 \mu \mathrm{m} / \mathrm{m}$. The autogenous shrinkage was automatically recorded every $10 \mathrm{~min}$, starting from about 30 min after mixing until 7 days.

\section{RESULTS AND DISCUSSIONS}

\section{Evolution of hydration degree}

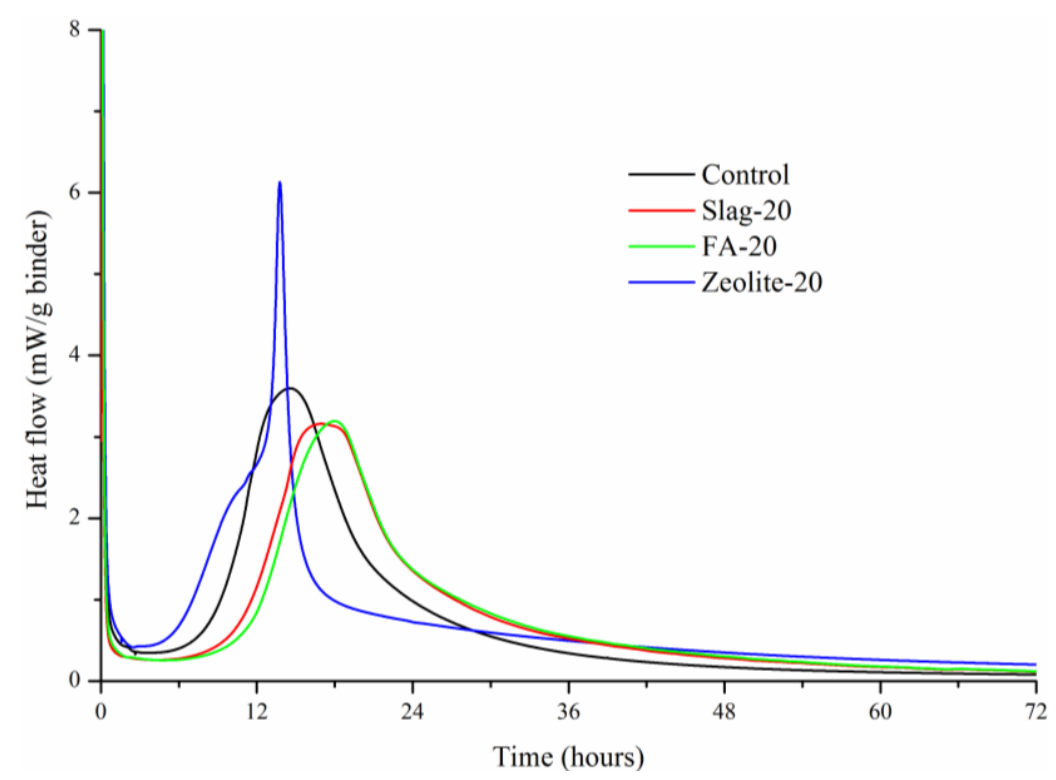

Figure 2. Evolution of hydration heat of cement paste blended with $\mathrm{SCMs}\left(20^{\circ} \mathrm{C}\right)$

The rate of hydration heat of the cement pastes blended with or without $20 \%$ SCMs are presented in Figure 2. For clarity reason, the heat flow results are plotted up to $72 \mathrm{~h}$. As shown in Figure 2, compared to the control paste, a shorter dormant period was observed in zeolite blended cement paste, indicating that zeolite blending contributed an acceleration effect on cement hydration. An obvious second peak during the acceleration period was also observed in zeolite blended paste, which might be due to the aluminum phase hydration. In additional, the deceleration period was much shorter for the zeolite blended paste compared to other three mixtures. However, zeolite blended paste showed a slightly higher rate of hydration reaction than those of other three mixtures after about 36 hours. This may indicate that the zeolite initially act as nucleating agents, speeding up the timing and rate of reactions, but are not contributing to the dilution effect often seen with fillers which tend to extend the magnitude of early age hydration [Lothenbach et al. 2011]. The slag blended paste showed a similar hydration heat release curve with that of fly ash blended paste. A longer dormant period and a lower maximum rate of heat release was observed both in slag and FA blended compared to the control paste, indicating that slag/FA blending results in a delay of the cement hydration. 


\section{Autogenous shrinkage}

According to ASTM C1698 [2009], the autogenous shrinkage was zeroed at the final setting time. Figure 3 shows the autogenous shrinkage zeroed to the final setting time as a function of time after mixing for the control and SCMs blended cement pastes. As shown in Figure 3, the control sample underwent a monotonic quick shrinkage till several hours after final setting, after which the sample showed another continuous shrink but with a much slower rate. Similar trend in the change of the autogenous shrinkage curves of pastes blended with SCMs was observed. At 7 days after mixing, FA blended paste showed the lowest autogenous shrinkage among the mixtures, while control sample showed the highest autogenous shrinkage. Slag blended paste showed less autogenous shrinkage than zeolite blended paste before 4 days; afterwards, higher autogenous shrinkage was observed in slag blended paste.

It has to be noted that the autogenous shrinkage is referenced to the length at final setting according to ASTM C1698 [2009]. However, the final setting time measured by Vicat needle is a very unreliable procedure. A high scatter in final setting time is usually obtained by Vicat needle measurement, it will have a large influence on the value of autogenous shrinkage, as the rate of shrinkage around final setting time is generally high.

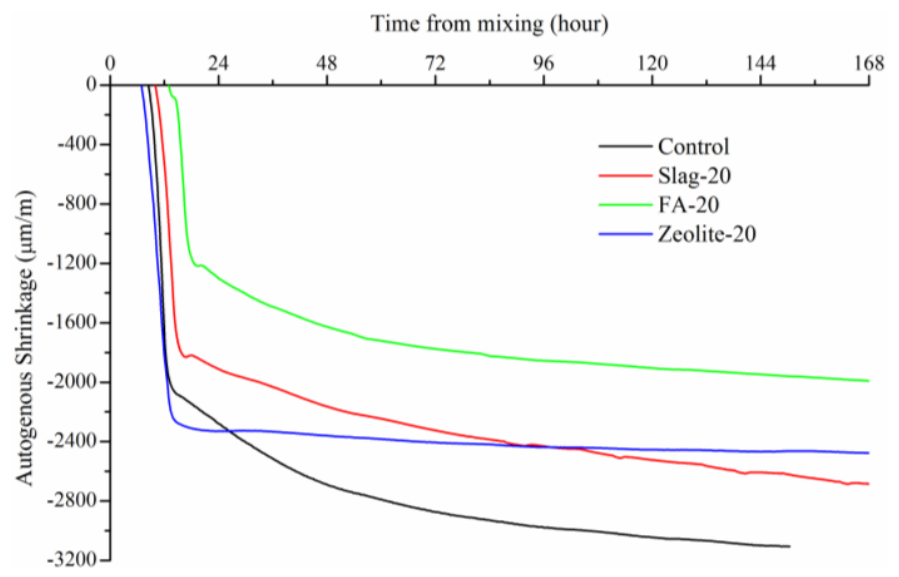

Figure 3. Autogenous shrinkage of cement paste blended with SCMs: zeroed at the final setting

\section{Relative humidity}

The development of internal RH with time is provided in Figure 4. As shown in Figure 4, the internal RH of control sample stabilized at around $98 \%$ till 13.8 hours after mixing, and then it showed a monotonic decrease to $80.3 \%$ at 3 days after mixing. Slag blended paste and FA blended paste showed similar trend in the development of internal RH. The internal RH began to drop at $17.1 \mathrm{~h}$ and $17.9 \mathrm{~h}$ to $87.9 \%$ and $86.8 \%$ at 3 days for slag blended paste and FA blended paste, respectively. The higher internal RH in slag and FA blended paste at 3 days is mainly due to the dilution effect. As cement was partially substituted by slag and/or FA, the effective water to cement ratio was higher than that in control sample. The zeolite blended paste showed a different behavior in the development of internal RH. It began to decrease quickly at 13.4 hours after mixing. And several hours later, it was followed by a slower decreasing. At 3 days after mixing, the internal RH was $94.2 \%$, which was higher than those of the control paste and slag/FA blended paste, indicating that the addition of zeolite as replacement of cement has a positive effect in the maintain of internal $\mathrm{RH}$ at high range, which is beneficial for the cement hydration (corresponding to the higher rate of hydration reaction after 36 hours, as shown in Figure 2). It is not due 
to the dilution effect, as the zeolite has a porous structure which can adsorb water during mixing, lowering the effective water to cement ratio. One possible explanation is that, due to its porous structure, the zeolite probably acts as an internal reservoir, providing a source of curing water to the paste in its vicinity during the hydration.

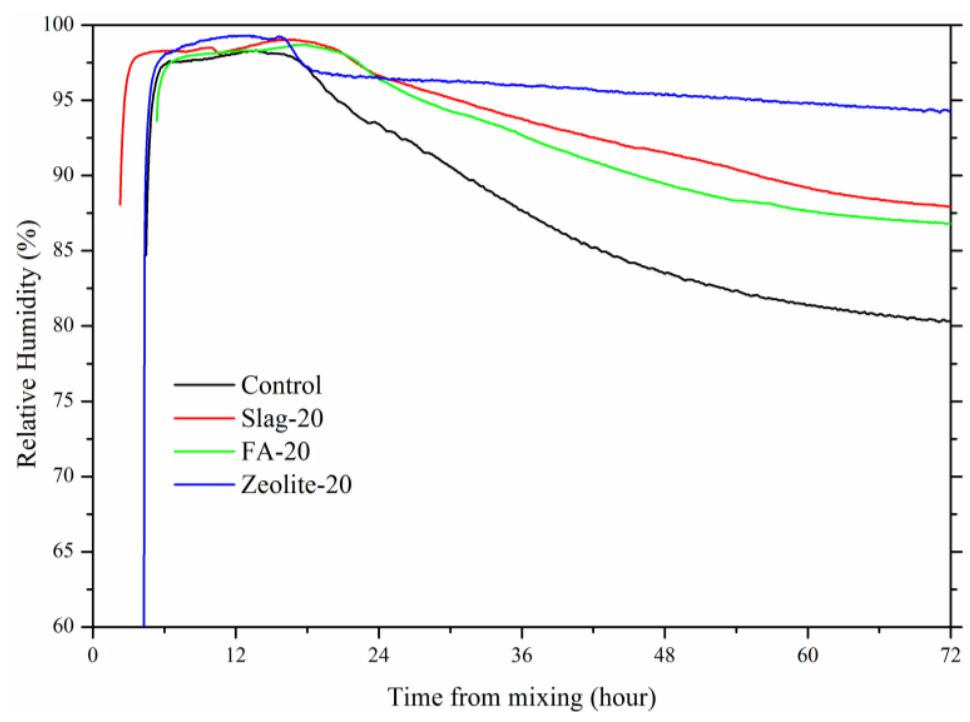

Figure 4. Internal relative humidity of cement paste blended with SCMs

\section{DISCUSSION}

One important problem involved in the research is the determination of "time-zero", i.e. the time for the start of autogenous shrinkage measurement. Deformations occurring before this "time-zero" can be ignored for stress calculation purposes, since they do not result in stresses. There is no general acceptance about the determination of this time, whether it corresponds to the initial setting, final setting, or some other time [Weiss 2002]. This lack of standardization causes great difficulty in direct comparisons between results provided in the existing literatures.

Although the mechanism of autogenous shrinkage is still under discussion, there is a general agreement about the existence of a relationship between autogenous shrinkage and internal $\mathrm{RH}$ changes in the pores of hardening cement paste. As long as the cement paste is fluid, the chemical shrinkage is totally converted into external volume change. When a solid skeleton forms in the hardening paste, the stiffness increases and gas bubbles start to nucleate and grow in the bigger pores due to the water consumption in the capillary pores. This leads to the formation of water-air menisci and the internal RH drops (Kelvin's law). The presence of menisci causes tensile stresses in the pore solution (Laplace's law) exerted on the solid skeleton, which leads to the autogenous shrinkage of cement paste [Jensen and Hansen 1996, 2001; Lura et al. 2003]. It is indicated that the autogenous shrinkage is part of the chemical shrinkage and is caused by the decrease of internal RH in pore structure. The solidification and the concurrent change of capillary pressure in the capillary pores start very slowly, and it is practically impossible to determine the precise onset of these processes. But the precise internal RH measurements of the pastes starting from the pastes are still in fluid phase supply reasonable experimental data to discuss the "time-zero" of autogenous shrinkage caused by self-desiccation. A systematic research about determining the "timezero" in low w/b ratio cement pastes was carried out by Huang and Ye [2014], and they came to the conclusion that the "time-zero" could be link to the time when internal RH begins to drop. 
Figure 5 displays the relation between the free shrinkage and the internal $\mathrm{RH}$ of the cement pastes as function of time from mixing. In Figure 5, the free shrinkage was zeroed at the casting time. It can be seen that no internal RH drop (self-desiccation) was observed at around the final setting time for each mixture, but the internal RH began to drop several hours after final setting time, corresponding to a knee point in the shrinkage curve. This time is the so-called new "time-zero". After the "time-zero", it developed a monotonic shrinkage at a much slower rate than that before the "time-zero", corresponding to the decrease of the internal RH (self-desiccation).
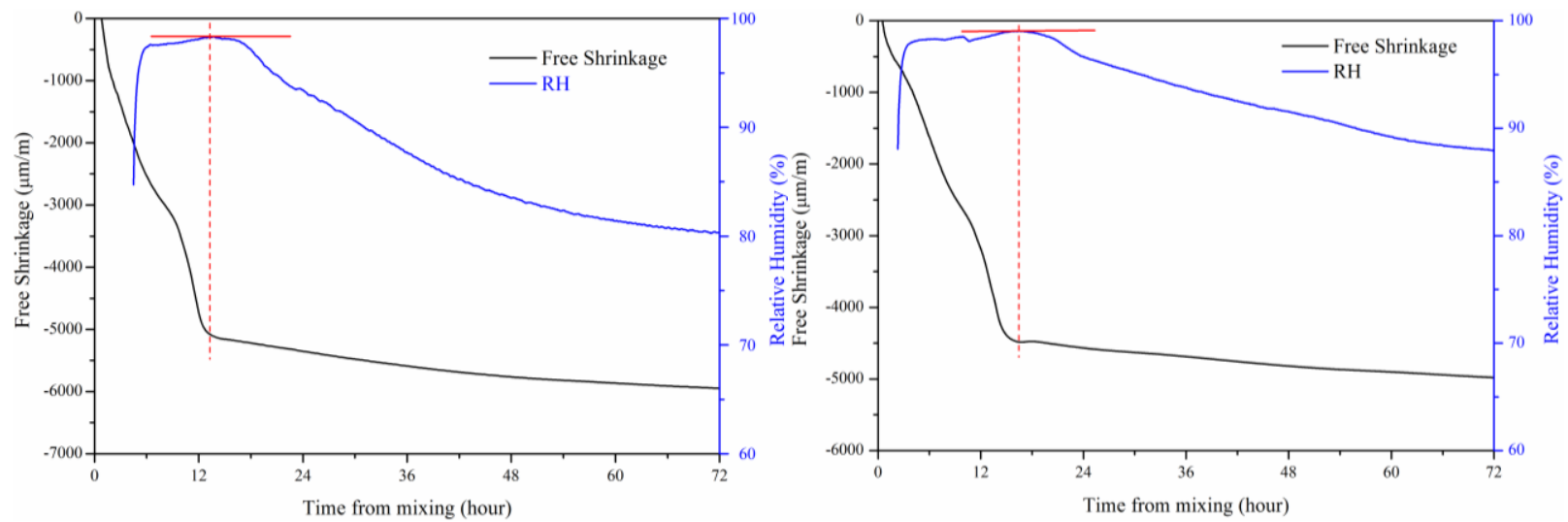

(a) control

(b) BFS 20
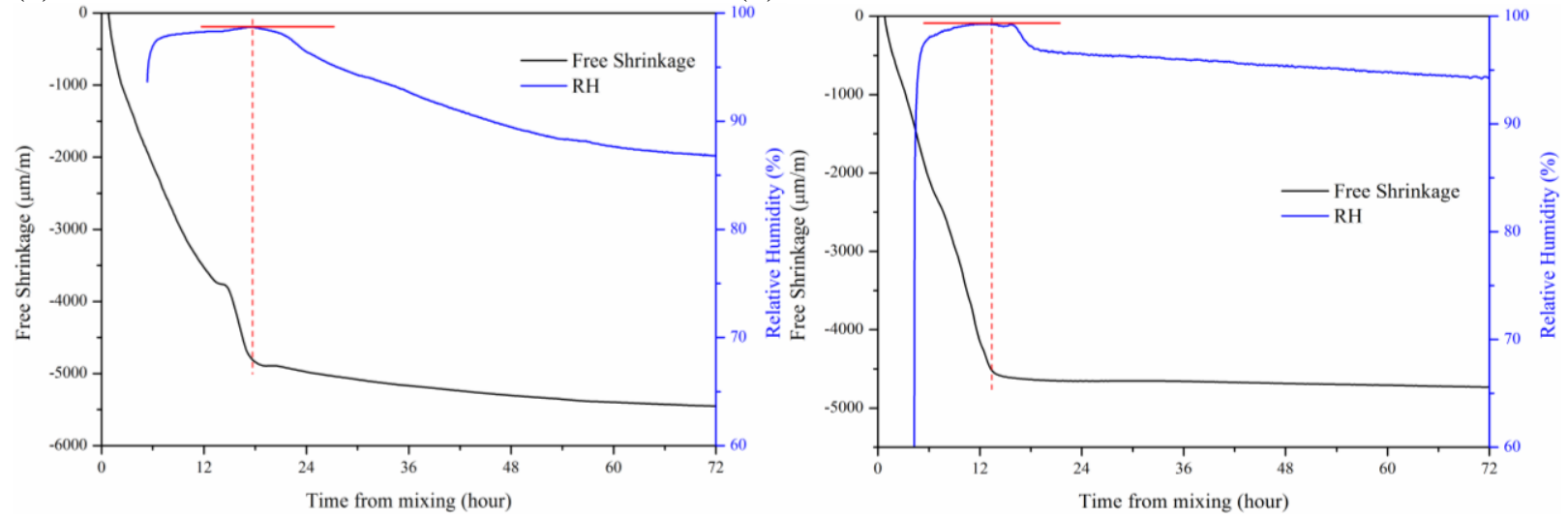

(c) FA 20

(d) Zeolite 20

\section{Figure 5. Relation between free shrinkage and RH of mixtures as function of time after mixing}

According to this new "time-zero", the autogenous shrinkage of each mixture was presented in Figure 6. As shown in Figure 6, control sample showed the highest autogenous shrinkage, which was $1057 \mu \mathrm{m} / \mathrm{m}$ at 6 days after mixing. A reduced autogenous shrinkage was observed in the blended paste. The behavior of autogenous shrinkage in paste blended with slag/FA seems to be related with the delayed hydration process (as shown in Figure 2). In additional, the internal RH in the slag/FA blended paste remained higher than that of control paste with the hydration proceeds, indicating a slower self-desiccation process (as shown in Figure 4); and subsequently the autogenous shrinkage was reduced. The autogenous shrinkage of slag blended paste and FA blended paste reached to $856 \mu \mathrm{m} / \mathrm{m}$ and $831 \mu \mathrm{m} / \mathrm{m}$ at 7 days, respectively. A lowest autogenous shrinkage was obtained in the zeolite blended paste, $337 \mu \mathrm{m} / \mathrm{m}$ at 7 days. The main reason for decrease in autogenous shrinkage is the poor occurrence of self-desiccation in zeolite blended paste. Due to its pore structure, the zeolite can absorb part of mixing water during mixing procedure, resulting in a lower effective water to binder ratio and the rapid decrease of internal $\mathrm{RH}$ 
during the first several hours (see Figure 4). Afterwards, the internal RH dropped to a relative low level, at which the absorbed water in the pores starts to be released to act as internal curing water and it can help counteracting the effects of self-desiccation and slow down the autogenous shrinkage.

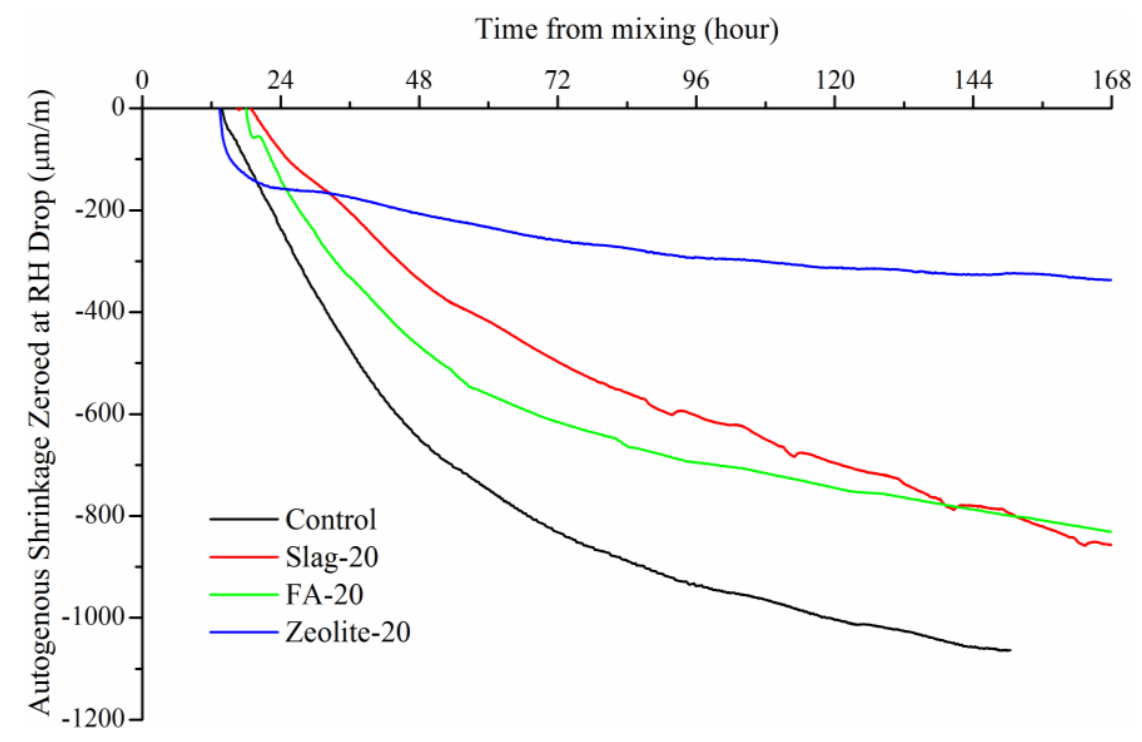

Figure 6. Shrinkage zeroed at the 'time-zero' defined by the onset of RH drop

\section{CONCLUSION}

This paper studies the early age autogenous shrinkage behavior of low w/b ratio cement paste blended with SCMs. Main findings can be made as follows.

(1) No self-desiccation was observed at the final setting time for each mixture; it begins to occur several hours later than the final setting time, corresponding to a knee point in the shrinkage curves. This point, the time when internal RH begins to drop, was selected as the "time-zero" for autogenous shrinkage.

(2) The cement paste blended with slag/FA shows a higher internal RH than that of control sample during the 3 days after mixing, indicating a slower self-desiccation process. The reduced autogenous shrinkage in slag/FA blended paste seems to be related to the slower self-desiccation and delayed hydration process.

(3) The cement paste blended with zeolite shows a highest internal RH among the selected materials in the present study. It is indicated that addition of zeolite could eliminate the self-desiccation partially, which is beneficial for the cement hydration. At the meanwhile, the autogenous shrinkage zeroed at the "time-zero" defined by the onset of RH drop is greatly reduced in the zeolite blended paste compared to control paste.

\section{ACKNOWLEDGEMENTS}

The authors acknowledge the financial support provided by the State Scholarship Program of China Scholarship Council and Special Research Fund from Ghent University. 


\section{REFERENCES}

ASTM C191 (2013). "Standard Test Methods for Time of Setting of Hydraulic Cement by Vicat Needle." ASTM International, West Conshohocken, PA.

ASTM C1698 (2009). "Standard Test Method for Autogenous Strain of Cement Paste and Mortar." ASTM International, West Conshohocken, PA.

Bentur A. (2001). "Comprehensive approach to prediction and control of early-age cracking in cementitious materials." in: F.-J. Ulm, Z.P. Bazant, F.H. Wittmann (Eds.), Creep, Shrinkage and Durability Mechanics of Concrete and Other Quasi-Brittle Materials , Proc. of Sixth Int. Conf., Elsevier Science Ltd., 589-598.

Bílek V., Keršner Z., Schmid P. (2002). “The possibility of self-curing concrete.” Innovations and developments in concrete materials and construction. September, Dundee, Scotland, UK 51.

Ghourchian S., Wyrzykowski M., Lura P., Shekarchi M., Ahmadi B. (2013). "An investigation on the use of zeolite aggregates for internal curing of concrete." Construction and Building Materials, 40, 135144.

Huang H., Ye G. (2014). "Examining the "Time-Zero" of autogenous shrinkage in cement pastes at low water cement ratio." In: V. Mechtcherine, C. Schoefl, ed. International RILEM Conference on Application of Superabsorbent Polymers and Other New Additives in Concrete Construction, 189200.

Jensen O.M., Hansen P.F. (1995). "A dilatometer for measuring autogenous deformation in hardening Portland cement past." Materials and Structures, 28, 406-409.

Jensen O.M., Hansen P.F. (1996). "Autogenous deformation and change of the relative humidity in silica fume-modified cement paste.” ACI Materials Journal, 93, 539-543.

Jensen O.M., Hansen P.F. (2001). "Autogenous deformation and RH-change in perspective." Cement and Concrete Research, 31, 1859-1865.

Justnes H., Reyniers B., Van Loo D., Sellevold E.J. (1994). "An evaluation of method of measuring chemical shrinkage of cementitious paste." Nordic Concrete Research, 14 (1), 45-61.

Krishnamoorthy T.S., Gopalakrishnan S., Balasubramian K., Bharatkumar B.H., Rama Moan Rao P. (2002). "Investigations on the cementitious grout containing supplementary cementitious materials." Cement and Concrete Research, 32, 1345-1405.

Lothenbach B., Scrivener K., Hooton R.D. (2011). "Supplementary cementitious materials." Cement and Concrete Research, 41, 1244-1256

Lura P., Jensen O.M., Van Breugel K. (2003). "Autogenous shrinkage in high-performance cement paste: an evaluation of basic mechanisms." Cement and Concrete Research, 33, 223-232.

Malhotra V. M., Mehta P.K. (1996). "Pozzolanic and cementitious materials." Advances in concrete technology, vol. 1. Canada: Gordon and Breach Publication.

Swamy R.N. (1997). "Design for durability and strength through the use of fly ash and slag in concrete." ACI SP, 171, 1-72.

Tazawa E., Miyazawa S., Shigekawa K. (1991). "Macroscopic shrinkage of hardening cement paste due to hydration." CAJ Proc. Cem. Concr. 45, 528.

Weiss J. (2002). "Experimental determination of the time-zero (maturity-zero)." In: A. Bentur ed, Early Age Cracking in Cementitious Systems-Report of RILEM Committee TC 181-EAS, RILEM Publications, Sarl, Bagneux, France, 195-206. 